\title{
GEOMETRIA RELACIONADA AO COTIDIANO
}

\author{
Alrineide de Melo Ferreira, Universidade Federal de Campina Grande (UFCG) \\ alryneidedlsjp@gmail.com \\ Rosinângela Cavalcanti da Silva, Universidade Federal de Campina Grande (UFCG) \\ professorarosinangela@gmail.com
}

\begin{abstract}
RESUMO
Como uma atividade da disciplina Estágio Supervisionado do Curso de Licenciatura em Matemática, foi elaborado o projeto Polígonos: Compreendendo Conceitos e Construindo Formas, baseado na necessidade do estudo da Geometria, buscando aperfeiçoar a qualidade desse ensino que é pouco trabalhado nas escolas atuais. Com o objetivo de desenvolver no aluno um novo olhar para a Matemática, mostrar a presença da geometria no dia a dia, bem como sua importância, conduzindo o educando a investigar, compreender e utilizar os conceitos, além das relações geométricas para resolver situações problemas e cotidianas. As aulas foram dirigidas por meio de conceitos, atividades dinâmicas, questionamentos, leitura, colagem, recortes, exercícios do livro didático e construção de cartazes, fazendo com que o aluno se motivasse a aprender o conteúdo de forma diferenciada e significativa, onde ele não só ouve o professor ou lê o que está no livro, mas constrói seu próprio conhecimento. A aplicação do projeto foi positiva entre os alunos, que mostraram interesse em conhecer algo novo, em construir e mostrar os resultados.
\end{abstract}

PALAVRAS CHAVES: Matemática; Polígonos; Geometria.

\section{INTRODUÇÃO}

A geometria ramo da matemática que estuda as formas é hoje pouco explorada nas escolas. Os educadores ministram esses conteúdos de modo que o aluno não consegue compreender o que é a geometria, a riqueza que ela proporciona para entender o mundo em sua volta. Baseando-se nisso é que é proposta uma metodologia de trabalho que busque desenvolver no aluno o prazer de estudar geometria e construir um conhecimento que vai além do ensinado atualmente. O ensino desse conteúdo deve ser feito a partir de aulas lúdicas, com o objetivo de fazer o aluno compreenderem o mundo em que vivem a partir do conceito de Geometria. Concordo com Lorenzo:

Sabemos que, por várias razões, a geometria não tem ocupado o seu devido lugar no ensino da matemática. Porém, é possível, desejável e necessário que o ensino dessa parte importante na Matemática seja fortemente enfatizado, 
porque, como já vimos, sem experiência geométrica não se consegue raciocinar geometricamente e, por consequência se constrói uma visão capenga, falaciosa e incompleta da matemática. (LORENZO, 2010, p. 3)

De fato, faz-se importante o estudo da geometria, pois a mesma proporciona ao indivíduo o conhecimento de formas e dimensões que levam a construir, explorar e reconhecer a geometria no cotidiano.

O trabalho com espaço e forma pressupõe que o professor de Matemática explore situações sem que sejam necessárias algumas construções geométricas com régua e compasso, como visualização e aplicação de propriedades das figuras, além da construção de outras relações. (BRASIL, 1998, p. 51)

Os professores devem estar aptos a buscar novas práticas pedagógicas e assim adquirir mais conhecimentos para ministrar os conteúdos, de forma que o aluno possa compreender o que está sendo transmitido em sala de aula e fazer uso daquilo que conhece. Segundo Lorenzo, (2010, p. 4) "o educando tem o direito de receber do professor um correto conteúdo tratado com clareza, e, por isso possa acontecer, é fundamental que o professor conheça a matemática e sua didática". Para que esse direito seja alcançado no ensino de geometria, em particular, é preciso desenvolver mecanismos diferentes dos tradicionais, ou seja, trazer para sala de aula além do livro didático outras formas de transmitir tal conhecimento, como objetos, imagens relacionadas com a geometria, para que o educando possa compreender sua relação com o cotidiano, segundo Pais:

Os recursos didáticos envolvem uma diversidade de elementos utilizados como suporte experimental na organização do processo de ensino e de aprendizagem. Sua finalidade é servir de interface mediadora para facilitar a relação entre professor, aluno e o conhecimento em um momento preciso da elaboração do saber. (PAIS, 1986, p. 5)

Almejando criar situações na aprendizagem que permitam aos alunos produzir materiais concretos no estudo das figuras planas, uma maneira de desenvolver conceitos geométricos, que serão de suma importância para compreender e poder representar o mundo 
em que vive, é que foram planejadas e desenvolvidas as atividades nas escolas através de um projeto de ensino.

\section{DESENVOLVIMENTO}

Como exigência da disciplina de Prática de Ensino de Matemática no Ensino Fundamental, foi feito um estágio de observação em escolas de Ensino Fundamental. Com isso, abriu-se uma discussão na sala, onde cada um falou da experiência nas observações das aulas de Matemática em diferentes turmas do ensino fundamental. Foi possível observar que a deficiência no conteúdo de Geometria é presente nas escolas. Tendo em vista a importância do conhecimento da geometria, esse projeto proporcionou trazer para os educandos um novo olhar para a Matemática, de modo que eles possam não só visualizar, mas também construir o conhecimento.

O estudo de Geometria foi desenvolvido por meio do conhecimento prévio, através da análise das formas das placas de trânsito, da praça, das casas, da igreja, entre outros, e desenvolvimento da construção de um novo conceito que permitiu aos mesmos compreender e identificar essas figuras no cotidiano fazendo uma relação com os polígonos estudados. O conteúdo de Polígonos, Formas Circulares e Simetria foi iniciado com a construção e um pouco da história da bandeira do Brasil, mostrando assim as formas geométricas que as compõem, a partir daí, iniciou-se o estudo dos polígonos, onde foi mostrado seus elementos (lados, ângulos e vértices) e as figuras que não são polígonos, através de atividade de colagem e construção de cartazes com os recortes dos polígonos. Os alunos participaram da aula, meio tímidos, mas conseguiram compreender, vir até a frente da classe, leram e falaram para os colegas sobre o que são polígonos. Logo depois, veio a classificação de polígonos com um cartaz mostrando as formas e uma atividade com cruzadinha e figuras para classificarem, mostrando na sequência o conceito de polígonos convexos, não convexos e regulares, finalizando com uma atividade dinâmica usando palitos de fósforo e cartolina. Os educandos se empolgaram nas atividades sugeridas, pintaram as formas geométricas da atividade, usaram os palitos fazendo figuras semelhantes a coisas do dia a dia, como casa e igreja e identificaram as formas usadas.

Posteriormente, foi ministrado o estudo dos triângulos com auxílio de formas triangulares levadas para a sala de aula, mostrando ainda sua classificação quanto as medidas 
dos lados e as medidas dos ângulos e foi feito a montagem de mosaicos e tangrans. Nessa ocasião, foi nítida a dificuldade de classificar triângulos, porém com as formas triangulares levadas para a sala de aula, ficou claro para eles, logo em seguida a atividade dinâmica envolveu todos, a sala foi dividida e equipes e cada uma procurou fazer um desenho diferente, mas que estava relacionado com o cotidiano deles.

Para dar continuidade ao conteúdo, foi desenvolvido o estudo dos quadriláteros, fazendo relações com o cotidiano dos alunos. Foram apresentadas formas circulares também fazendo relações com o dia a dia, nessa ocasião os educandos usaram o compasso para desenhar a circunferência. Os alunos tiveram dificuldade para entender o conteúdo no início, porém a associação de quadriláteros com o campo de futebol, com a bandeira nacional fez com que ficasse mais perto do conhecimento de mundo que já tinham e acabaram fazendo desenhos de estádio de futebol. O que mais chamou atenção dos discentes foi o uso do compasso para construir a circunferência. Para a maioria, era algo novo, que não conheciam, nem se quer sabiam segurar e abrir o compasso adequadamente.

As formas simétricas foram abordadas com exemplos em cartazes de figuras simétricas e assimétricas, os alunos foram estimulados a fazerem recortes, identificar o eixo de simetria e fazer colagens nos cadernos, identificando a posição do eixo (horizontal, vertical ou diagonal), além de resolver questões. Por fim, foi feita uma exposição de todos os trabalhos construídos durante o estágio, no qual os alunos apresentaram para uma turma do $7^{\circ}$ ano da referida escola. Essa foi a parte mais empolgante, era possível perceber a dedicação e o esforço da maioria deles para expor os trabalhos. Mesmo tímidos na hora de falar, mas conseguiram mostrar os cartazes que confeccionaram, além dos trabalhos feitos em sala de aula.

\section{CONCLUSÃO}

A aplicação do projeto Polígonos: Compreendendo Conceitos e Construindo Formas, foi de suma importância na minha formação enquanto educadora pude ver de perto a realidade da escola atual, além da oportunidade de contribuir para a formação dos educandos, trazendo para o ambiente escolar uma forma mais prazerosa de adquirir tal conhecimento.

Mostrar para os alunos a relação da matemática com o cotidiano, sobretudo da Geometria e trazer para a sala de aula uma metodologia que contribuísse com um aprendizado 
mais eficaz do conteúdo transmitido e de levá-lo a construir e relacionar a matemática com o cotidiano.

Depois do trabalho realizado ficou nítido que os alunos se identificaram com a prática pedagógica implantada, e com isso conclui-se que a maneira com que o professor faz a situação didática para desenvolvimento dos conteúdos contribui diretamente para o desenvolvimento dos discentes.

Baseado nisso, abre-se um novo olhar que por meio da experiência do estágio sei que devo procurar sempre buscar mecanismos que facilitem o aprendizado dos alunos em relação aos conteúdos de Matemática.

\title{
GEOMETRY RELATED TO THE DAILY
}

\begin{abstract}
As an activity of the Supervised Internship Course of the Licentiate Course in Mathematics, the project Polygons: Understanding Concepts and Constructing Forms was elaborated, based on the necessity of the study of Geometry, seeking to improve the quality of this teaching that is little worked in the current schools. With the objective of developing in the student a new look at Mathematics, showing the presence of geometry in everyday life, as well as its importance, leading the learner to investigate, understand and use the concepts, as well as geometric relationships to solve problem situations and Everyday life.

The classes were directed through concepts, dynamic activities, questioning, reading, collage, clippings, textbook exercises and poster construction, making the student motivated to learn the content in a differentiated and meaningful way, where he not only Listens to the teacher, or reads what is in the book, but constructs his own knowledge. The application of the project was positive among the students, who showed interest in knowing something new, in building and showing the results.
\end{abstract}

KEYWORDS: Mathematics; Polygons; Geometry;

\section{GEOMETRÍA RELACIONADA AL COTIDIANO RESUMEN}

Como una actividad de la disciplina Etapa Supervisada del Curso de Licenciatura en Matemáticas, se elaboró el proyecto Polígonos: Entendiendo Conceptos y Construyendo Formas, basado en la necesidad del estudio de la Geometría, buscando perfeccionar la calidad de esa enseñanza que es poco trabajado en las escuelas actuales. Con el objetivo de desarrollar en el alumno una nueva mirada a las matemáticas, mostrar la presencia de la geometría en el día a día, así como su importancia, conduciendo al educando a investigar, comprender y utilizar los conceptos, además de las relaciones geométricas para resolver situaciones problemas y De la vida cotidiana. 
Las clases fueron dirigidas por medio de conceptos, actividades dinámicas, cuestionamientos, lectura, collage, recortes, ejercicios del libro didáctico y construcción de carteles, haciendo que el alumno se motive a aprender el contenido de forma diferenciada y significativa, donde él no sólo Oye al profesor o lee lo que está en el libro, pero construye su propio conocimiento. La aplicación del proyecto fue positiva entre los alumnos, que mostraron interés en conocer algo nuevo, en construir y mostrar los resultados.

PALABRAS CLAVES: Matemáticas; Polígonos; Geometría;

\section{REFERÊNCIAS BIBLIOGRÁFICAS}

BRASIL, Ministério da educação. Secretária da Educação Fundamental. Parâmetros Curriculares Nacionais: Matemática, v.3. Brasília: MEC, 2001.

BRASIL, Ministério da educação. Secretária da Educação Fundamental. Parâmetros Curriculares Nacionais: Matemática. Brasília: MEC, 1998.

FREIRE, Paulo. Pedagogia da Autonomia. São Paulo: Paz e Terra, 2011.

LORENZATO, Sergio. Para Aprender Matemática. 3.ed. rev. Campinas, SP: Autores Associados, 2010. (Coleção Formação de Professores).

PAIS, Luiz Carlos. Uma Análise de Significado da Utilização de Recursos Didáticos no Ensino da $\quad 2000 . \quad$ Geometria. http://www.ufrrj.br/emanped/paginas/conteudo_producoes/docs_23/analise_significado.pdf 